\title{
Research on Hybrid Temperature Measurement Method for High Speed Motorized Spindle
}

\author{
Li-xiu zhang ${ }^{1,}$ a , Jin-peng $L i^{2}$, b* and Chao-qun $\mathrm{Li}^{3, c}$ \\ 1,2,3 Nationai-Local Jiont Engineering Laboratory of NC Machining Equipment and Technology of \\ High-Grade stone, \\ School of Mechanical Engineering,Shenyang Jian Zhu University,Shenyang,China 110168; \\ a851617088@qq.com, b453011045@qq.com, c734500010@qq.com
}

\begin{abstract}
Keywords: Motorized spindle Temperature rising Contacted temperature measurement Infrared temperature measurement.
\end{abstract}

Abstract. Temperature measuring method is one of the key issues in the research of high speed motorized spindle of thermal characteristics.In this paper, a new hybrid temperature measurement method is proposed, which is based on the contacted temperature measurement and infrared temperature measurement experiments, and using least square curve fitting and error compensation as a method. A temperature model of 170SD30-SY high speed and high precision motorized spindle is established,to measure a wider range and obtain a preciser temperature field of motorized spindle.The modified hybrid temperature measured as a minimum of $0.01{ }^{\circ} \mathrm{C}$ and a maximum of $1.19{ }^{\circ} \mathrm{C}$

\section{Introduction}

High speed motorized spindle is one of the core functions of CNC machine tools, and its performance directly determines the technical level of $\mathrm{CNC}$ machine tools ${ }^{[1]}$. The high temperature rise and thermal deformation of the motorized spindle will affect the rotation accuracy of the spindle, even the service life ${ }^{[2]}$. Therefore, the thermal characteristics of the motorized spindle is an important part of the research work of motorized spindle.

The selection of temperature measurement method is one of the key technologies of thermal characteristic research.Temperature measurement is the premise to describe the change of temperature, so the method of temperature measurement has aroused the enthusiasm of domestic and foreign experts.Otakar Horejs ${ }^{[3]}$ measured the temperature of the horizontal milling center by thermal resistance as a input of transfer function (TTF)compensation algorithm,to predict the direction Z of displacement of the machine.Chuang Chen ${ }^{[4]}{ }^{i n s t a l l e d ~ t h e r m a l ~ r e s i s t a n c e ~ o n ~ a ~ v e r t i c a l ~ m a c h i n i n g ~}$ center for temperature monitoring. Through the temperature monitoring,they found spindle speed and the maximum temperature difference when the spindle reach to thermal equilibrium.Hong Yang ${ }^{[5]}$ installed 11 thermocouples in the motor bearing and ball bearing and so on,to simulate actual machining condition of machine tool and measure the temperature rise of each part.Cheng-Hsien $\mathrm{Wu}^{[6]}$ used thermocouples to monitor the temperature field of a $\mathrm{CNC}$ milling machine.Mayr. ${ }^{[7]}$ obtained the infrared image of the spindle of the three axis milling machine by infrared photography instrument.E.Uhlmann ${ }^{[8]}$ collected the temperature field of the spindle under $15000 \mathrm{rpm}$ field after 150 min by infrared thermal imager

The method of temperature monitoring for machine tools is summarized, which mainly has contact temperature measurement and non-contact temperature measurement.In this paper, a new hybrid temperature measurement method is proposed, which is based on the contact temperature measurement as basis and infrared temperature measurement experiments as a compensation.

\section{Technology analysis temperature monitoring for high speed motorized spindle}

The contacted temperature measurement can measure the superficial temperature of motorized spindle, and the internal temperature of spindle should be required to punch,and the rotating parts of the spindle would not be measured.In particular,the rotation shaft temperature of spindle could not be measured because of high speed and the sensor can not be installed. When we use the non-contact 
infrared thermal imaging system to measure the temperature rise of the motorized spindle, the measuring range is wide, and the temperature of the shaft can be measured.However the error is bigger than contact temperature measurement method.So,in this paper,we hope to explore an infrared temperature measurement, and compare with contact temperature measurement method,to compensate for the error of infrared temperature measurement,as figure 1 shows.In order to establish a simple, convenient, stable and reliable measurement method, which can monitor temperature in real-time and adapt to the working environment of machine tools temperature.

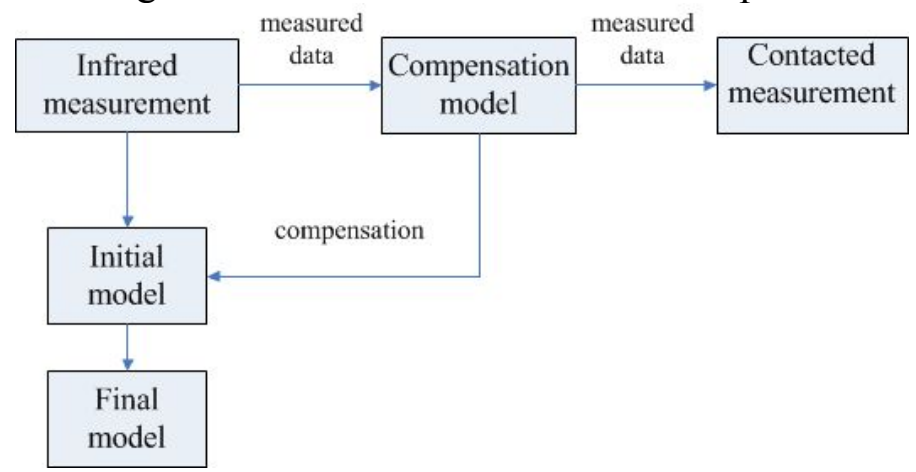

Figure.1 Temperature compensation model

\section{Hybrid Temperature Measurement Method for High Speed Motorized Spindle}

In this experiment,the hybrid temperature measurement is proposed by infrared measurement, combined with contacted measurement.Figure. 2 is the experimental device of hybrid measurement.Under the same experimental conditions, the same test points which test with contacted temperature measurement and infrared temperature measurement methods respectively are selected for temperature measurement analysis. The motorized spindle type NO. is 170SD30-SY.The experimental process of temperature measurement is as follows:110 contact type temperature sensors are installed in the surface of spindle where the front bearing,the rear bearing and middle of front and rear bearing span; Then,two infrared thermal imager start to measure the real-time temperature;(2)At the beginning,the water cooling control system and oil-gas lubrication control system power should be opened and adjust the pressure of the air compressor to $P=0.72 M P a$ for the purpose to ensure the pressure of the compressed air into the bearing is $P_{a}=0.4 M P a$, the inlet air temperature is $\mathrm{T}_{a}=20^{\circ} \mathrm{C}$; The inlet water temperature is $\mathrm{T}_{w}=20^{\circ} \mathrm{C}$, the flow is $q=0.32 \mathrm{~m}^{3} / \mathrm{h}$; (3) Set a speed of $n=10000 \mathrm{r} / \mathrm{min}$ and no-load operation.

In Figure2 with contacted temperature measurement,these points are collected once per $5 \mathrm{~min}$ and automatically recorded.In infrared temperature measurement scheme,temperature of motorized spindle is real-time monitoring by two infrared thermal imager,with the type of SC6X5 A615 from US company FLIR, as shown in Figure 2.The thermal imager can not only visual display the temperature field of the surface of the spindle, but also can record the temperature changes at different time and the data storage and processing.It shows the measured temperature distribution of the motorized spindle running 60mins in Figure 2, and the image is obtained by the thermal imager analysis software BM_IR. 

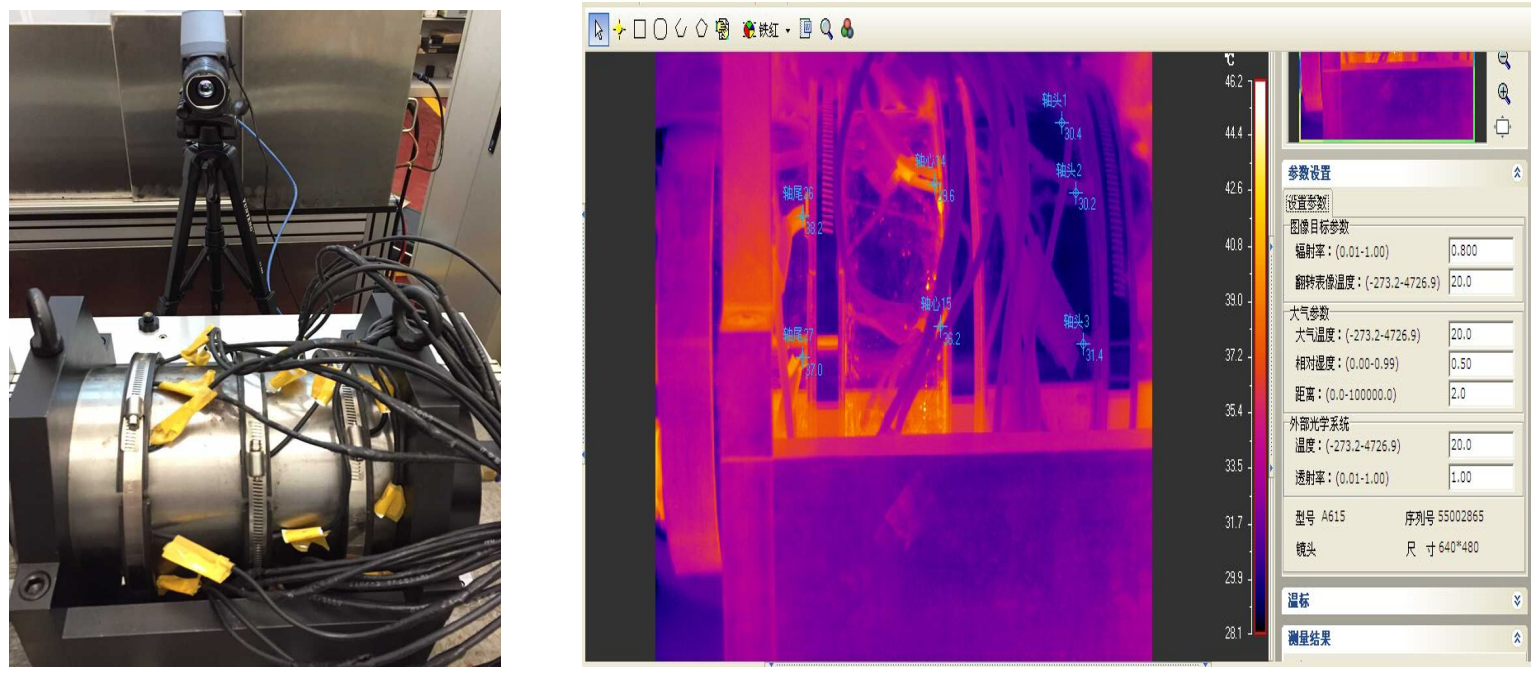

Figure.2 Hybrid temperature measurement device

Comparison of measurement results.According to the experimental data, the comparison results of the two methods are obtained.There are 10 monitoring points in the circumferential direction in the contact temperature measurement, and the monitoring point of the infrared type can be randomly selected.In this paper,in order to facilitate the monitoring and processing of data, each position takes 4 monitoring points, and then take the average value of the analysis.Then, the average temperature of each position of 4 points is plotted.Figure 3 is the temperature curve of motorized spindle in different position. The left one is the temperature contrast curve between the contacted type and infrared type of front bearing. The middle is the position in which the middle of front and rear bearing span.The last one is the temperature contrast diagram between the contacted type and infrared type of rear bearing.Moreover,the red ones above, which is higher,is recorded by the thermal imager. The other is recorded by contacted measurement.As can be seen from the figures, it is clearly that temperature variation trend is consistent. The temperature error of different position is different, with the maximum of 1.94 , the minimum of 0.42 .
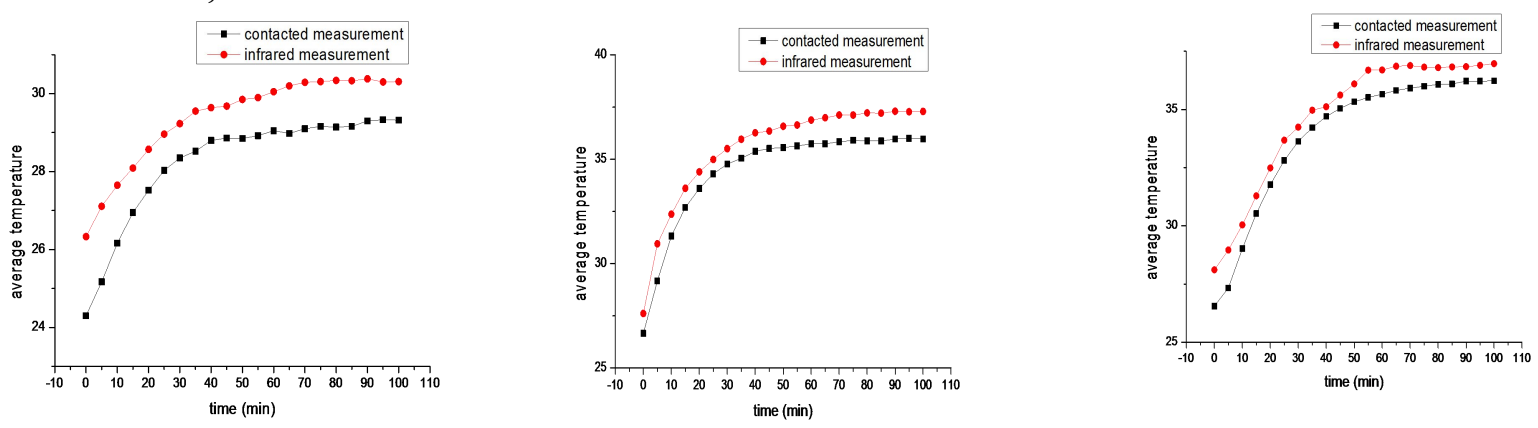

Figure 3.The temperature curve of the motorized spindle in different position

\section{Temperature model of high speed motorized spindle based on hybrid measurement method}

The trend of temperature variation of motorized spindle surface can be seen from figure.3.The temperature variation is generally approximated to a power function curve $T=a t^{b}$, with $\mathrm{t}$ means time and $\mathrm{T}$ means temperature. By least squares, fitting the curve of $T_{i}=a_{i} t^{b_{i}}(\mathrm{i}=1,2,3$ respectively represents front bearing,middle of front and rear bearing span and rear bearing).At the same tine, in order to give full play to the advantages of infrared measurement, it requires that using the data obtained by contact measurement method modify the data by infrared thermal imagers, to get a $\Delta_{i}$. So,the temperature model of motorized spindle,after hybrid measuring, is that $T_{i}=a_{i} t^{b_{i}}-\Delta_{i}$. Here in order to facilitate analysis, the temperature model in the middle of front and rear bearing span is analyzed only.

Curve fitting part,curve fitting for infrared temperature measurement in middle of front and rear bearing span,is transformed into fitting a power function of $S^{*}\left(t_{j}\right)=a t_{j}^{b}$ with the average 
temperature experimental data for 4 points $\left\{\left(t_{j}, T_{j}\right), j=1,2,3 \ldots 20\right.$ represent 20 time nodes, same as below $\}$.For error $\delta_{i}=S *\left(t_{j}\right)-T_{j}$, get $\sum_{j=1}^{20} \delta_{j}^{2}=\min \sum_{j=1}^{20}\left[S *\left(t_{j}\right)-T_{j}\right]^{2}$.Least squares fitting is the square of the error and the minimum.Curve approximation is known as a power function of $T_{j}=a t_{j}^{b}$, taking logarithm of the equation both sides.Let be $\overline{T_{j}}=\ln T_{j}, A=\ln a$, then get $\overline{T_{j}}=A+b t_{j}$.Let linear independence function family be $\varphi=\left\{1, t_{j}\right\}$.In order to determine $\mathrm{A}$ and $\mathrm{b},\left(t_{j}, T_{j}\right)$ is transformed into $\left(t_{j}, \bar{T}_{j}\right)$.According to the least squares method,let be $\varphi_{0}(t)=1, \varphi_{1}(t)=t_{j}$. Respectively determined $\left(\varphi_{0}, \varphi_{0}\right)=\sum_{j=1}^{20} t_{j}^{0},\left(\varphi_{0}, \varphi_{1}\right)=\sum_{j=1}^{20} t_{j},\left(\varphi_{1}, \varphi_{1}\right)=\sum_{j=1}^{20} t_{j}^{2},\left(\varphi_{0}, \overline{T_{j}}\right)=\sum_{j=1}^{20} \bar{T}_{j}^{2},\left(\varphi_{1}, \overline{T_{j}}\right)=\sum_{j=1}^{20} t_{j} \bar{T}_{j}$, to get a normal equation. Then $\mathrm{A}$ and $\mathrm{b}$ is obtained from the equation,so return to the front equation to get $\mathrm{a}=28.49$ and $\mathrm{b}=0.06176$.Hence, the initial model of infrared temperature measurement in the middle of front and rear bearing span is $T=28.49 \mathrm{t}^{0.06176}$.

Error compensation part,infrared temperature measurement will get a error compensation from contacted temperature measurement.For position of the middle of front and rear bearing span, $\Delta=\sum_{j=1}^{20}\left(T_{j}^{i n}-T_{j}^{c n}\right) / 20$ is obtained,with $T_{j}^{i n}$ means infrared temperature and $T_{j}^{\text {cn }}$ contacted temperature.After calculating, $\Delta=1.11$ is obtained.So the final model of infrared temperature measurement in the middle of front and rear bearing span is $T=28.49 \mathrm{t}^{0.06176}-1.10$. In the same way, the other two equations can be worked out.

Therefore,after modifying, temperature measuring equations of the front bearing,middle of front and rear bearing span and rear bearing respectively are obtained as below.

$$
\begin{aligned}
& T_{1}=25.34 \mathrm{t}^{0.04099}-1.10 \\
& T_{2}=28.49 \mathrm{t}^{0.06176}-1.11 \\
& T_{3}=25.11 \mathrm{t}^{0.08876}-0.83
\end{aligned}
$$

By the obtained equation,the modified temperature of infrared measurement is calculated.Table 1 is that the comparing between the former data before with the modified.

\begin{tabular}{|c|c|c|c|c|c|c|c|c|}
\hline Code & $\begin{array}{l}\text { Time } \\
(\min )\end{array}$ & $\begin{array}{c}\text { Infrared } \\
\text { measurement } \\
\text { temperature }\end{array}$ & $\begin{array}{c}\text { Contacted } \\
\text { measurement } \\
\text { temperature }\end{array}$ & Error & $\begin{array}{c}\text { Relative } \\
\text { error }\end{array}$ & $\begin{array}{c}\text { Modified } \\
\text { Infrared } \\
\text { measurement } \\
\text { temperature }\end{array}$ & $\begin{array}{c}\text { Modified } \\
\text { error }\end{array}$ & $\begin{array}{l}\text { Modified } \\
\text { relative error }\end{array}$ \\
\hline 1 & 5 & 30.95 & 29.17 & 1.78 & $6.10 \%$ & 30.36 & 1.19 & $4.08 \%$ \\
\hline 2 & 10 & 32.37 & 31.32 & 1.05 & $3.35 \%$ & 31.73 & 0.41 & $1.31 \%$ \\
\hline 3 & 15 & 33.61 & 32.69 & 0.92 & $2.81 \%$ & 32.57 & 0.12 & $0.37 \%$ \\
\hline$\ldots$ & $\ldots$ & $\cdots$ & $\cdots$ & & & $\cdots$ & $\ldots$ & $\ldots$ \\
\hline 18 & 90 & 37.3 & 35.97 & 1.33 & $3.70 \%$ & 36.51 & 0.54 & $1.50 \%$ \\
\hline 19 & 95 & 37.28 & 36.00 & 1.28 & $3.56 \%$ & 36.63 & 0.63 & $1.75 \%$ \\
\hline 20 & 100 & 37.29 & 35.97 & 1.32 & $3.67 \%$ & 36.75 & 0.78 & $2.17 \%$ \\
\hline
\end{tabular}

Table. 1 The temperature and relative error of infrared measurement before and after the modification 
The above table shows that,for infrared temperature measurement in middle of front and rear bearing span ,the average error is $1.11^{\circ} \mathrm{C}$, and the average relative error is $3.20 \%$;after modified,the average error is $0.47^{\circ} \mathrm{C}$, and the average relative error is $1.37 \%$.

In the same way to calculate,for the front bearing,the average error is $1.10^{\circ} \mathrm{C}$, and the average relative error is $3.91 \%$; after modified,the average error is $0.22^{\circ} \mathrm{C}$, and the average relative error is $0.81 \%$.For the rear bearing,the average error is $0.83^{\circ} \mathrm{C}$, and the average relative error is $2.48 \%$; after modified, the average error is $0.47^{\circ} \mathrm{C}$, and the average relative error is $1.40 \% .1$

\section{Conclusion}

(1)In this paper, taking the advantages of infrared temperature measurement and contact temperature measurement,a new hybrid temperature measurement method is proposed.It can measure a wide range,and get a real-time and preciser temperature field,improving the measurement accuracy of the temperature of motorized spindle.

(2) The modified hybrid temperature measured as a minimum of $0.01{ }^{\circ} \mathrm{C}$ and a maximum of $1.19{ }^{\circ} \mathrm{C}$

(3)The thought and method and the modified model provide the basis for intelligent control of temperature rise of motorized spindle.

\section{Acknowledgment}

This research is supported by The National Natural Science Foundation of China(No.51375317) and Science and Technology Innovation Major Project of Liaoning Province,China(No.201301001).

\section{References}

[1]Yuhou Wu,Lixiu Zhang.Control Technology of High Speed Motorized Spindle CNC Machine[M].Beijing,Science Press,2013.

[2]Han Xu,Liangling Luo..Research on On-line Temperature Monitoring System for Motorized Spindle[J].Journal of Nanchang University(Engineering\&Technology)Vol.30No.1,Mar.2008

[3]Otakar Horejs, et al. Advanced modeling of thermally induced displacements and its implementation into standard CNC controller of horizontal milling center [J]. Procedia CIRP,2012,4:67-72

[4]Chuang Chen, Jianfu Zhang, Zhijun $\mathrm{Wu}$, et al. A real-time measurement method of

temperature fields and thermal errors in machine tools[C]. Proceeding of the 2010 International Conference on Digital Manufacturing\&Automation. ChangSha, Hunan China. 2010, (1):100-103.

[5]Hong Yang et al. Dynamic modeling for machine tool thermal error compensation[J].Journal of Manufacturing Science and Engineering, 2003, 125(2): 245-254.

[6]Cheng-Hsien Wu, Yu-Tai Kung. Thermal analysis for the feed drive system of a CNC machine center[J]. International Journal of Machine Tools\&Manufacture, 2003, 43(15):1521-1528.

[7] Mayr J, et al. Comparing the Thermo-mechanical behaviour of machine tool frame designs using a FDM-FEM simulation approach[C]. Proceedings ASPE Annual Meeting, 2007, 1:17-20

[8] E.Uhlmann, et al. Thermal modeling of a high speed motor spindle[C]. Procedia CIRP, 2012,1:313-318. 